\title{
REFLEXÕES TEÓRICAS E METODOLÓGICAS SOBRE PESQUISAS NO CAMPO DA SAÚDE MENTAL E TRABALHO
}

\author{
Roberto Heloani \\ Eduardo Pinto e Silva
}

\section{Resumo:}

Discutem-se neste texto os aspectos teórico-metodológicos das pesquisas nas Ciências Sociais, com destaque às do campo da saúde mental e do trabalho. Aponta-se para a potencialidade da complementaridade da adoção de procedimentos quantitativos e qualitativos de pesquisa e do enfoque teórico interdisciplinar. O conceito de desgaste mental no trabalho dominado é elemento-chave para interlocuções de distintos modelos teóricos. Apresentamos uma análise comparativa de pesquisas com guardas municipais e jornalistas, de modo a ilustrar a pertinência de nossos argumentos. Concluímos apontando o potencial crítico e transformador da perspectiva histórico-dialética e psicodinâmica das pesquisas do campo da saúde mental e trabalho.

Palavras-chave: Aspectos teórico-metodológicos. Saúde mental e trabalho, Materialismo histórico-dialético. Psicodinâmica do Trabalho.

\section{THEORETICAL AND METHODOLOGICAL REFLECTIONS ON RESEARCH IN THE FIELD OF MENTAL HEALTH AND WORK}

\begin{abstract}
:
Theoretical-methodological aspects of research in Social Sciences are here discussed, with emphasis on those in the field of mental health and work. It points out to the potential of complementarity in the adoption of quantitative and qualitative research procedures and the interdisciplinary theoretical approach. The concept of mental exhaustion in dominated work is a key element for the interlocution of different theoretical models. We present a comparative analysis of research with municipal guards and journalists in order to illustrate the pertinence of our arguments. We conclude by pointing out the critical and transforming potential of the historical-dialectical and psychodynamic perspective of research in the field of mental health and work.
\end{abstract}

Keywords: Theoretical-methodological Aspects. Mental Health and Work. Historicaldialectical Materialism. Work Psychodinamic.

\section{Introduzindo a questão}

Diferentes saberes do campo científico, concernentes à temática da pesquisa em psicologia do trabalholsaúde do trabalhador vêm paulatinamente considerando a questão da compreensão, interpretação e empatia como crucial para um melhor entendimento de um campo 
que hoje se fragmenta em diferentes abordagens, paradigmas e, mesmo por que não dizer, epistemologias (HELOANI; LANCMAN, 2004).

A compreensão da dialética entre a dimensão quantitativa e qualitativa configura fundamento vital para a interpretação e a análise das interações complexas dos fenômenos que ocorrem nessa área. Em nosso entender, a episteme de caráter quantitativo aprrsenta em seu bojo a qualidade conceitual e categorial, tal como a abordagem qualitativa apenas disfarça mal - que não consegue prescindir totalmente da esfera quantitativa, haja vista o crescente número de sofisticados programas computacionais na área das ciências humanas e sociais que utilizam - e muito - os sistemas informacionais cuja base é a matemática e a estatística aplicada. É, em síntese, o convite para pensar uma realidade que não é mais aquela compartimentada das ciências contidas em câmaras separadas, mas a ciência transdisciplinar, ou melhor, a "ciência com consciência", como tem advogado Morin (1994) em sua obra.

Não é nossa intenção discutir aqui, com maior amplitude, o tema da interdisciplinaridade, o que exigiria um ensaio à parte, mas apenas indicar por que motivos a efetiva ocorrência dessa condição, expressa no vasto campo epistemológico da "Psicodinâmica do Trabalho"/Psicanálise, não nos esmorece na busca de novas veredas e formas de relação entre as diferentes áreas do saber - mesmo porque nos baseamos no pressuposto de que a cisão entre a unidade e o múltiplo não é verdadeira senão na aparência, pois a palavra universal, etimologicamente falando, abarca o conceito de unidade e de multiplicidade. "Unis" significa um e "diversitas", diversos, múltiplos. Ou seja, a unidade implica necessariamente diversidade e vice-versa ((HELOANI; LANCMAN, 2004).

Ademais, o saber é resultado de uma construção histórica e, assim, pode-se averiguar que a interdisciplinaridade do saber é a face subjetiva da coletividade dos sujeitos constituintes. É, portanto, um processo tal como a própria vida, onde o singular, o particular e o universal não se excluem. Ao contrário, no âmbito do pensamento hegeliano, o singular não nega o universal, apresenta traços comuns e contradições na busca de uma conciliação ou superação.

$\mathrm{Na}$ dialética hegeliana, o real existe como dinâmica contraditória e processual, o quantitativo gerando o qualitativo, de modo tal que ambos possam se conhecer e se reconhecer simultaneamente. No nosso entender, não há quantidade que não implique qualidade, nem tão pouco qualidade destituída da possibilidade de quantificação, pois tudo o que existe "vem a ser" com base no que está sendo, gerando uma correlação tensional benéfica entre abordagens distintas e complementares. Essa é a nossa posição.

Assim sendo, a metodologia de pesquisa qualitativa é uma alternativa de pesquisa possível, com foco multimetodológico e que envolve uma abordagem hermenêuticointerpretativa (compreensiva) do objeto de estudo. Dessa forma, a pesquisa qualitativa é uma designação ampla que congrega várias correntes de pensamento, que têm como denominador comum o enfrentamento do modelo positivista enquanto padrão único de ciência.

Não pretendemos desmerecer a metodologia da pesquisa quantitativa, até porque discordamos daqueles que indiscriminadamente a criticam. A nossa experiência como pesquisadores sinaliza para situações nas quais existirão acontecimentos em que a apreensão do objeto exige ou recomenda a utilização de ambas as abordagens - quantitativa e qualitativa - e permite trazer à luz dimensões verificadas nas pesquisas quantitativas que perderiam sua riqueza e contribuição se fossem reduzidas unicamente à dimensão quantitativa. Como 
quantificar determinadas características observáveis nas investigações que privilegiam a escuta dos participantes sem as empobrecer e as esvaziar do conteúdo singular que trazem?

O "a priori", em uma concepção quantitativa, vem escoltado por variáveis definidas e hipóteses claramente especificadas. O termo hipótese - do grego "hipos", inferior, equino concerne a tese que ainda não se resolveu, ou melhor, que ainda não podemos provar. Assim sendo, é uma solução possível. Sempre é uma afirmação provisória, testável, que pode vir a ser falsa ou verdadeira e depende da coleta e análise dos dados. Portanto, pode ser a solução do problema de pesquisa ou não. A descrição e a observação - que podem chegar à explicação almejam a precisão dos resultados.

Às vezes, o problema não é solucionado e convém modificar a pergunta. Não há demérito na aferição de que a hipótese é falsa, até porque é uma afirmação provisória. O que não é muito honroso é falsear os dados... para "provar a hipótese"!

Sob o abrigo do termo "pesquisa qualitativa", coabitam alguns tipos de investigação fundamentados em distintas concepções teóricas, prevalecendo entre elas as orientações filosóficas da dialética e da fenomenologia e os enfoques metodológicos da etnometodologia e mesmo do interacionismo simbólico.

Na contramão do que alguns pesquisadores, por vezes pouco experientes no uso dessas metodologias, pensam, embora a pesquisa qualitativa busque a compreensão (esfera da linguagem) e implique certa "empatia" (capacidade de colocar-se no lugar do outro) em relação aos fenômenos humanos e sociais que pretende interpretar (hermenêutica), essa abordagem de investigação exige por parte do pesquisador rigor metodológico e certa experiência no trato dos documentos, entrevistas e, mesmo, observações pessoais.

Portanto, à luz da hermenêutica e das mentalidades o pesquisador busca compreender o significado que as pessoas dão a sua vida. Sobretudo pela lógica relacional, nessa perspectiva, o investigador preocupa-se mais com o processo do que com os resultados, tendo como base questões amplas, que vão se tornando mais focadas com base nos dados, da definição do objeto e da compreensão do quadro referencial.

Por conseguinte, acreditamos que a estratégia e os procedimentos metodológicos utilizados no processo de construção de um trabalho científico dependem da natureza do problema que se deseja estudar. Quando necessitamos explorar o objeto de estudo na fase inicial ou quando a quantificação não faz sentido, devido à exiguidade do universo de pesquisa, a pesquisa qualitativa se impõe. Mas não é só. Quando a pesquisa tem por objetivo descortinar os sentidos e significados que as pessoas utilizam ao se depararem com o mundo e o que se procura é a compreensão do fenômeno em sua totalidade, a opção pela abordagem qualitativa parece-nos a mais adequada.

\section{Sobre distintas perspectivas de pesquisa nas Ciências Sociais e no campo da saúde e trabalho}

No campo das Ciências Sociais há uma concordância sobre os três grandes eixos teóricometodológicos apontados por Löwy (1985): positivismo, historicismo e marxismo. Toma-se como pressuposto a inexistência da neutralidade do pesquisador, ao mesmo tempo que se aponta para a necessidade do rigor teórico-metodológico e suas distintas formas de cumprir a 
rigorosidade do método científico. A assunção de qualquer uma das perspectivas não escapa da relação entre ideologia, conhecimento, prática social e política.

No positivismo se situam distintas formulações sobre a ciência livre de juízo de valor. Löwy (1986) considera ser, dentre essas, a mais "profunda", "interessante" e "propositiva", a de Max Weber, que embora não seja apontado como um autor positivista, em seu sentido clássico, comungaria com a referida ideia de ciência livre de juízo de valores. De modo geral, a hipótese fundamental do positivismo é a da "sociedade humana" regida por "leis naturais" e "invariáveis" que "regulam o funcionamento da vida social, econômica e política", aspecto este que de fato afasta Weber da condição de típico autor positivista (LÖWY, 1985. p.35-36).

Löwy (1985) considera o amplo espectro do positivismo, de modo a sair do senso comum de ser simplesmente uma perspectiva funcionalista ou reprodutora do status quo. Indica, por exemplo, na "matemática social" de Codorcet, um "caráter utópico" e até mesmo "revolucionário" desta que considera ser a "primeira formulação do positivismo" (LÖWY, 1985, p.37). Não é nosso intuito nos alongarmos na caracterização de tal perspectiva, mas ela inclui vários autores clássicos, como Saint-Simon ("fisiologia social), Comte ("física social") e Durkheim, que influenciam sobremaneira muitos autores e pesquisas contemporâneos, de modo mais ou menos assumido, até mesmo pelos que se assumem como historicistas ou marxistas. A importância dada à empiria, à objetividade e ao concreto é algo presente no positivismo, o que nenhum pesquisador sério e comprometido, mesmo que o critique e adote outra perspectiva, poderia deixar de reconhecer.

O historicismo, seguindo a caracterização de Löwy (1985, p.69-70), parte de "três hipóteses fundamentais":

1. Qualquer fenômeno social, cultural ou político é histórico e só pode ser compreendido dentro da história, através da história, em relação ao processo histórico. 2. Existe uma diferença fundamental entre os fatos históricos ou sociais e os fatos naturais. Em consequência, as ciências que estudam estes dois tipos de fatos, o fato natural e o fato social, são ciências de tipo qualitativamente distintos. 3. Não só o objeto de pesquisa é histórico, está imergido no fluxo da história, como também o sujeito da pesquisa, o investigador, o pesquisador, está, ele próprio, imerso no curso da história, no processo histórico; (LÖWY, 1985, p.69-70).

Ao tecer essa caracterização, Löwy (1985) pondera que existem formas de ciência social que são de vertente ao mesmo tempo positivista e historicista, mencionando Max Weber, assim como aponta para a existência de uma vertente historicista do marxismo e até mesmo para uma tendência de um marxismo positivista. Portanto, se assinala demarcações e distinções importantes entre os três eixos teórico-metodológicos, não cai na simplificação e tampouco ignora suas possíveis interpenetrações e interlocuções, que, diga-se de passagem, nos parecem tão desejáveis como necessárias, dentro do rigor e distanciamento do que seria um ecletismo ingênuo.

O historicismo é sem dúvida uma perspectiva fundamental nas Ciências Sociais e na teoria do conhecimento social. Löwy (1985) enfatiza que a concepção historicista percebe com acuidade a relação entre valores (ideologias ou visão de mundo) e o processo do conhecimento científico, e se refere ao fundador da sociologia do conhecimento, Karl Mannheim. No historicismo refuta-se a ideia de que uma ciência histórica possa ser, grosso modo, 
completamente objetiva. Tal parece uma crítica importante ao positivismo, ao mesmo tempo em que pode deslizar para um relativismo que se torna criticado ou criticável pelo marxismo. O importante a assinalar é que há o reconhecimento da existência de uma relação de identidade entre sujeito e objeto, o que é apontado por Löwy, com base na discussão de proposições diversas, como as de Dilthey, Simmel, Weber, Mannheim e até de Lukács (que influenciou, como Marx, o pensamento mannheimiano em suas pesquisas sociológicas sobre a episteme e a forma de apreender o mundo. Karl Mannhein, preocupado com o fenômeno geracional, adverte que certas vivências reunidas no curso da vida não se acumulam meramente por adição e empilhamento, mas se articulam dialeticamente. Ou melhor, para o pensador alemão, embora o conceito de gerações represente, antes de qualquer coisa, uma crítica ao positivismo de Auguste Comte (1978), não se resume a isso. A conceituação fina se dá em algumas passagens textuais, nas quais o autor afirma que vemos as coisas com uma determinada configuração, ou seja, algo que se assemelha a uma "Gestalt"

Vemos as coisas com uma determinada com figuração. Pensamos os conceitos com uma significação determinada. Em cada caso, a certeza se dá através do grupo que sempre há por trás dos outros. Crescer em um grupo significa captar aqueles aspectos das coisas, aqueles matizes das significações dos conceitos, aquela configuração dos conteúdos anímico-espirituais com as quais uns e outros estão presentes para o grupo. (MANNHEIM, 1982).

É conhecida a crítica de Marx e Engels (1999) à dialética hegeliana ou à ideologia como uma especulação metafísica que inverte a realidade. O marxismo critica a visão idealista. Aí sua proposta de virar de ponta cabeças a dialética hegeliana. Mas o materialismo-histórico dialético não nega a objetividade ressaltada pelo positivismo, nem tampouco a importância dada pelo historicismo à história. Mas o faz de modo peculiar e dialético, o que significa um esforço de síntese ou de superação da dicotomia entre o idealismo e o objetivismo. A questão da classe social é intrínseca às proposições do marxismo e as relações sociais não são passíveis de serem analisadas divorciadas da análise do trabalho e do modo de produção e reprodução social. As contribuições da obra de Marx (2013) partem do estudo dos economistas liberais e de Hegel (2014) e Lukács (2010) segue o mesmo caminho ao aprofundar as relações entre trabalho (protoforma de toda prática social), reprodução social, ontologia do ser social e o papel da subjetividade na história. Contradições, processos, considerações históricas e recusa à toda e qualquer simplificação de compreensão da realidade concreta com base em relações de causa e efeito são marcas indeléveis do pensamento marxista crítico à sociedade expropriadora. A alienação não é vista de forma fatalista, pois enseja estranhamento, e este, a conscientização e práticas sociais alternativas, sempre dentro de constrangimentos e possibilidades da causalidade posta e das propriedades do ser social, tal como apregoa Lukács (2010).

De modo similar a Löwy, mas com terminologias ligeiramente distintas, Gamboa (2000) aborda a dialética na pesquisa em educação. Aponta para sua importância como alternativa teórico-metodológica. Em sua análise da produção em tal área, Gamboa (2000) indicou uma categoria metodológica fundamental: a relação entre o lógico e o histórico. São apontados os três eixos teórico-metodológicos das pesquisas, denominadas como "empírico-analíticas", "fenomenológico-hermenêuticas” e “crítico-dialéticas” (GAMBOA, 2000, p.94). 
Para contextualizar a dialética na pesquisa em educação, Gamboa (2000) busca caracterizar as perspectivas empírico-analíticas e hermenêutico-dialéticas e as condições históricas que permitiram seus surgimentos e desenvolvimentos. Justifica sua empreitada pelo fato da pesquisa dialética apresentar uma

$$
\begin{aligned}
& \text { "pretensão de síntese" que, segundo seu argumento, "não é ecletismo } \\
& \text { nem soma de partes ou tópicos vindos de outras abordagens", mas, } \\
& \text { outrossim, "uma nova maneira de ver, conceber e organizar } \\
& \text { categorias", muitas delas "originadas de outras visões", mas } \\
& \text { "recriadas" em "novas condições" e outros "interesses" (GAMBOA, } \\
& \text { 2000, p.95). }
\end{aligned}
$$

$\mathrm{Na}$ abordagem empírico-analítica prevalece a compreensão da pesquisa como um processo técnico de descrição e explicação que deve ser separado de valores e propostas políticas ("neutralidade axiológica"), ao passo que a abordagem fenomenológico-hermenêutica critica seus fundamentos no experimentalismo, métodos quantitativos e propostas tecnicistas (GAMBOA, 2000). Como diria Löwy (1985) ao descrever o historicismo, a perspectiva hermenêutica busca decifrar "ideologias subjacentes" ou "desvendar e decifrar os pressupostos implícitos nos discursos, textos ou comunicações” (GAMBOA, 2000, p.97). Por sua vez, em sua "pretensão de síntese", a perspectiva crítico-dialética caracteriza-se por questionamento à "visão estática da realidade" que estaria "implícita nas abordagens anteriores", ou seja, certa tendência a ocultar o "conflito de interesses" (de classes sociais antagônicas), manifestando o seu "interesse transformador" e "desvendando" as "possibilidades de mudança" (GAMBOA, 2000, p.97). Esta crítica, porém, não implica recusa de uma forma particular de apropriação:

Desde sua elaboração como método de pesquisa científica (Marx), a dialética tem pretendido aproveitar os elementos gerados dentro das abordagens empíricas (empirismo inglês) e das abordagens fundadas nos postulados da fenomenologia (idealismo alemão), realizando sínteses entre essas duas grandes tendências filosóficas. Hoje a dialética aplicada à educação não escapa a essa pretensão. Surge como nova opção entre a pesquisa empíricoanalítica e a fenomenológica-hermenêutica, apropriando-se, no nível de nova síntese, de algumas categorias desenvolvidas nessas duas abordagens. (GAMBOA, 2000, p.94).

De forma relativamente similar, no campo das pesquisas da saúde e do trabalho, Seligmann-Silva $(1995 ; 2011)$ propõe um "paradigma integrador" de distintos modelos teórico-metodológicos. O conceito de desgaste é chave para tal. Originalmente desenvolvido em sua obra de 1994, "O desgaste mental no trabalho dominado" (reeditada e ampliada em 2011), sob influência da perspectiva materialista histórico-dialética de Laurell e Noriega (1989). O desgaste relaciona-se a múltiplos aspectos: biopsíquicos, psicossociais, organizacionais, institucionais e sociais. Ainda, à degradação do trabalhador e do trabalho, à degradação da identidade, da saúde e dos ideais éticos e políticos, aspectos estes indissociáveis dos processos históricos de intensificação e precarização social e do trabalho (DAL ROSSO, 2008). 
Seligmann-Silva (2011) encara o desafio interdisciplinar e aponta para três eixos teórico-metodológicos dos estudos sobre saúde e trabalho: estudos do "workstress" ("abordagens que têm suas raizes na teoria do estresse"), cujo modelo provém da "perspectiva positivista" e da "visão behaviorista"; estudos da "Psicodinâmica do Trabalho" ("corrente voltada para a utilização do referencial psicanalítico") que ensejam pesquisas qualitativas, intervenções organizacionais e compreensão crítica dos processos de adoecimento e estratégias defensivas dos trabalhadores e o modelo que adota o conceito de desgaste, cujo fundamento teórico original foi o do "materialismo dialético e a perspectiva histórica" de Laurell e Noriega (SELIGMANN-SILVA, 2011, p.122s.).

Seligmann-Silva (2001, p.126-128), ao mesmo tempo em que descreve as críticas à concepção positivista, reconhece os méritos do trabalho pioneiro de Selye (1946; 1965), assim como os avanços das abordagens derivadas de suas proposições, tal como na proposta do modelo tridimensional do ambiente psicossocial do trabalho de Karasek (1979) e de outros autores que apontam para os "fatores psicossociais" do adoecimento (e não propriamente os "determinantes sociais", vistos de forma mais ampla e crítica), como Glina (2010). O fato é que os aspectos psicossociais do adoecimento passam a ser mais bem evidenciados pelos modelos teóricos de estresse e estresse no trabalho. Uma apreciação crítica de tais desenvolvimentos e do aprofundamento da compreensão do nexo causal entre trabalho e doença são evidenciados em capítulo de Schmidt et alii (2018). Tal capítulo se insere em coletânea organizada por Schmidt, Castro e Casadore (2018), na qual também são identificadas produções que Seligmann-Silva (2011) indica serem fundamentadas na Psicanálise. Trata-se de importante compilação que permite a interlocução das distintas contribuições de modelos teóricos diferentes para a compreensão dos fatores psicossociais e do processo de saúde/doença no trabalho, seus aspectos teóricos, metodológicos interventivos e preventivos.

\section{Considerações interdisciplinares sobre a metodologia de pesquisa em saúde mental e trabalho}

Primeiramente devemos justificar a importância tanto da realização como da discussão ou problematização das pesquisas na área de saúde mental e trabalho. Vale salientar que, no contexto histórico da reestruturação produtiva, a precarização das relações de trabalho, a intensificação do ritmo de trabalho e a exigência de polivalência têm agravado os problemas de saúde ocupacional (HELOANI; SILVA, 2006).

Segundo nossa concepção, o trabalho tem uma função psíquica (constituição da identidade e da subjetividade) e engendra um espaço social de reconhecimento, de gratificação e de mobilização da inteligência (DEJOURS, 1993), de modo que os impedimentos para que tal aconteça, delimitados pelo horizonte de (im)possibilidades do atual momento histórico, devem ser sistematicamente analisados em prol de sua superação.

Para nós, o trabalho é a matriz da integração social e as propostas de intervenção e de transformação do trabalho devem objetivar a substituição do sofrimento/adoecimento pelo prazer/desenvolvimento (do coletivo e da instituição). Tais considerações relacionam-se à abordagem da Psicopatologia e Psicodinâmica do Trabalho (DEJOURS, 2004a; 2004b; 1994; 1993; 1992; HELOANI; LANCMAN, 2004) e a de outras abordagens interdisciplinares e críticas da grande área da Psicologia Social, Organizacional e do Trabalho (ENRIQUEZ, 1995; HELOANI, 1996; 1997; SATO, 1998; SELIGMANN-SILVA, 1995; PAGÈS, 1987). 
A Psicodinâmica do Trabalho é uma abordagem teórico-metodológica em saúde mental e trabalho problematizada e interpretada por distintos autores brasileiros. Contribuir para tal debate e polêmica é um fundamento ético que nos move, e que move autores acima indicados (SATO, 1998; SELIGMANN-SILVA, 1995).

Segundo Jacques (1995), os referenciais da Sociologia e da Psicologia Social, ou ainda, o referencial freudomarxista (SILVA, 2013), propiciam elucidar os nexos e as articulações indispensáveis entre identidade e trabalho. Embora possamos apontar tanto para as diferentes ênfases entre a abordagem (clínica) de base psicanalítica da Psicodinâmica do Trabalho e as abordagens (sociológicas) de base marxista, ambas alinham-se à metodologia qualitativa, ao passo que as abordagens cognitivo-comportamentais que utilizam o conceito de stress podem ser caracterizadas pelo uso de metodologias quantitativas (JACQUES, 2003).

Jacques (2003) considera que há tentativas de se procurar empregar conceitos e procedimentos de origens diversas. A abordagem de Seligmann-Silva (1995), considerada por nós interdisciplinar e fundamentada por um "paradigma integrador", tal como a identifica a autora (SELIGMANN-SILVA, 1995, p.294), não é citada por Jacques (2003). Do nosso ponto de vista trata-se de perspectiva efetivamente imbuída do esforço de construção de uma abordagem sincrética, crítica e politizada dos processos de saúde-doença no trabalho.

Jacques (2003) agrupa e classifica as metodologias e as abordagens teóricas das pesquisas em saúde mental e trabalho. Ela as denomina como: "teorias sobre estresse", "psicodinâmica do trabalho", "modelo epidemiológico elou diagnóstico" e "estudos e pesquisas em subjetividade e trabalho”. A classificação de Seligmann-Silva (1995), pioneira e mais genérica, evita a difícil categorização mais pormenorizada e preserva a coerência em relação à etiologia das ideias de alguns autores ou abordagens que abarcam tanto divergências como convergências. Consideramos que nossa abordagem do stress enquanto processo dialético de desgaste sócio-organizacional e biopsíquico (HELOANI; SILVA, 2006; SILVA, 2005) distingue-se da visão positivista, ainda que adotemos o instrumento ISS (LIPP; GUEVARA, 1994) como recurso para identificar a porcentagem e a fase do stress em trabalhadores. Argumentamos ainda que não é toda abordagem acerca do stress que se coaduna com a visão médico-biológica de caráter naturalizante, individualizante e biologizante.

De modo geral, concordamos com Jacques (2003; 1995) em relação aos seguintes pontos: o entendimento de que a abordagem comportamental-cognitivista, fundamentada na metodologia quantitativa, relaciona-se à Psicologia Social Científica (compreendida por nós como funcionalista); b) as demais abordagens, entre elas a psicodinâmica (dejouriana) e a sociológica (marxista), com base, sobretudo, na metodologia qualitativa, relacionam-se "em maior ou menor grau", conforme o autor, aos pressupostos da "psicologia social históricocrítica" (JACQUES, 2003, p.113); c) a compreensão de que a abordagem interdisciplinar é relevante para explicitarmos a articulação indispensável entre trabalho e identidade.

Compreendemos, tal como Seligmann-Silva (1995), que uma abordagem integradora da metodologia da pesquisa em saúde mental e trabalho é o desejável, tendo em vista a realidade complexa e multifacetada do seu objeto de estudo. Tal abordagem, que relaciona a subjetividade ao econômico, ao político e ao institucional, incorpora conceitos da Psicodinâmica do Trabalho à análise materialista histórico-dialética (SILVA, 2013). A autora considera que o enfoque integrador, por ela defendido, supera tanto o viés objetivista quanto o subjetivista, de modo que inclui, em seu bojo, as visões politizadas e psicodinâmicas do sofrimento psíquico e/ou do 
adoecimento no trabalho, assim como os fatores objetivados pelos estudos do workstress. Nas palavras da autora:

O modelo centrado no conceito de desgaste mental pode ser tomado como um paradigma integrador, que permite compreender as interações entre os 'fatores' objetivados pelos estudos do 'workstress', a subjetividade e diferentes esferas da vida social, a partir dos âmbitos microssociais do local de trabalho e da família, passando pelos intermediários (empresa e comunidade), até os macrossociais, que definem desde a divisão internacional de trabalho às políticas industrial, tecnológica e salarial de cada país, balizando as relações sociais de trabalho em cada realidade. (SELIGMANNSILVA, 1995, p.294).

De nossa parte compreendemos que se faz necessário um amplo esforço no sentido de superar as compreensões simplificadas acerca do stress, tanto daquelas sintomaticamente produzidas no cotidiano, como também daquelas produzidas no próprio campo científico que, não raramente, tendem a individualizar, biologizar ou mesmo despolitizar o fenômeno.

No que tange às modalidades do discurso científico sobre o stress, acreditamos que é necessário abordar criticamente a concepção biologizante que se fez historicamente dominante com base nas contribuições originais da Medicina (SELYE, 1946; 1965) e subsequentes da Psicologia Comportamental-Cognitiva (LIPP, 1996; 2000).

Baseamo-nos no pressuposto de que o ser humano é uma unidade biopsicossocial e de que o fenômeno do stress jamais será compreendido, de forma crítica e em sua complexidade etiológica, ontológica e processual, se prescindirmos de alguns conceitos e/ou de noções-chave advindos de distintas contribuições a ele direta ou intrinsecamente articulados, a saber: "fadiga" e "carga psíquica" no trabalho (DEJOURS, 1992; 1994); "desgaste mental no trabalho dominado" (SELIGMANN-SILVA, 1994); "processo saúde-doença” (LAURELL; NORIEGA, 1989).

Destacamos a visão de Seligmann-Silva (1994; 1995) que explicita a intenção de elaborar compreensões teóricas que, muito embora critiquem as visões biologizantes ou positivistas (ou mesmo individualizantes, também presentes na facção eminentemente clínica da Psicanálise), não as menospreza, além de integrar os referidos pressupostos da Psicodinâmica do Trabalho. Seligmann-Silva (1995, p.289) considera que o trabalho "vem sendo reconhecido como importante instância na patogenia, no desencadeamento e na evolução de distúrbios psíquicos", reconhecimento este por ela relacionado a um crescente interesse pela temática da "psicopatologia do trabalho". Apesar dos estudos na área serem cada vez mais numerosos, ainda não haveria um consenso firmemente estabelecido acerca do modo como se exerce a "conexão trabalho/psiquismo" (BORGES, 1997; SATO, 1998; SELIGMANN-SILVA, 1995, p.289). Embora sejam estudadas as determinações coletivas do distúrbio psíquico (sobretudo o aspecto patogênico da organização do trabalho), estas inevitavelmente se articulam aos modos individuais ou singulares de interação e de adoecimento (AUBERT, 1994, p.163-193), ou ainda, aos processos sociais que se situam aquém e além do mundo do trabalho propriamente dito.

A autora afirma que "o modelo centrado no conceito de desgaste mental pode ser tomado como um paradigma integrador" (SELIGMANN-SILVA, 1995, p.294), e acrescenta: "no conceito de desgaste mental é possível integrar a ideia de um desgaste concreto em nível 
orgânico", com a ideia de um desgaste psicossocial (desgaste da esperança em relação ao projeto de vida e/ou deterioração da autoimagem e da autoestima).

Seligmann-Silva (1995, p.293s.) aponta que o campo da saúde mental e do trabalho, com a variedade de seus modelos teóricos e diferentes enfoques, permite múltiplas leituras dos fenômenos da fadiga, do stress, das neuroses do trabalho, da alienação e da dominação, tanto nos ambientes de trabalho como na vida social de modo geral. A crítica mais contundente ao modelo que tem suas raízes na teoria do stress de Selye $(1946$; 1965) é a de que se trata de um modelo mecanicista e unidirecional, conivente com a noção de normalidade (CANGUILHEM, 2002) e condizente com os interesses dos "donos do poder e da produção"; ou ainda, por ser um modelo que ignora a "dimensão política” do stress (SELIGMANN-SILVA, 1995, p.293s.). Apesar dessa crítica, como antes mencionado, considera que tal modelo teve dois importantes desdobramentos: um no qual aspectos psicodinâmicos passaram a ser incluídos, configurando o conceito de burnout ("esgotamento profissional"), e outro no qual se priorizou a análise de aspectos sociais do stress, quer seja relacionando-o à organização do trabalho, quer seja relacionando-o aos diferentes tipos de apoio social que atuam (ou não) na adaptação (ou na nãoadaptação) às situações estressoras (SELIGMANN-SILVA, 1995, p.293). Ainda seguindo Seligmann-Silva (1995, p.294), o modelo dejouriano acrescenta importantes reflexões ao modelo positivista e aos seus dois desdobramentos. Com base em tal modelo, os aspectos psicodinâmicos e psicossociais do stress podem ser efetivamente explicitados. Conforme ainda esclarece a autora, o estudo da Psicodinâmica do Trabalho, ao utilizar o referencial psicanalítico e, ao mesmo tempo, absorver contribuições de várias disciplinas (sobretudo daquelas que estudam a organização do trabalho em uma perspectiva psicossocial), permite-nos melhor elucidar as estratégias de defesa e/ou de solidariedade individuais e coletivas em relação a questões como medo e sofrimento no trabalho. A autora aponta que:

Alguns pesquisadores têm procurado criar convergências entre as duas correntes, adotando abordagens nas quais associam técnicas que permitem mensuração de elementos visíveis e procedimentos do tipo qualitativo, voltados para o entendimento das dinâmicas que se processam no nível profundo das estruturas psíquicas e sociais. (SELIGMANN-SILVA, 1995, p.294).

Concordamos com a referida pesquisadora quando a mesma considera que, embora possamos identificar algumas aproximações entre os dois referidos modelos, há entre eles diferenças conceituais e de enfoque que não são desprezíveis. Por um lado, o modelo positivista e seus desdobramentos não consideram a "dimensão política" do stress. Por outro, o modelo dejouriano não dá a devida atenção aos apoios sociais que se originam fora do ambiente de trabalho e que influenciam a maior ou menor vulnerabilidade do trabalhador em relação a seus aspectos patogênicos mais circunscritos ou específicos da gestão e da organização do trabalho (SELIGMANN-SILVA, 1995, p.294).

Compreendemos que o modelo proposto por Seligmann-Silva (1995, p.294) pode efetivamente consolidar-se como um "terceiro caminho", ou seja, como um "paradigma integrador" passível de superar os impasses teóricos e de abordagens presentes tanto nos distintos modelos de análise como nas mencionadas tentativas de os articular.

O desgaste no trabalho dominado (SELIGMANN-SILVA, 1995, p.294; 1994) é compreendido como "um produto de uma correlação desigual de forças no processo 
biopsicossocial saúde-doença”. Nesse processo, determinações de ordem sociopolítica e econômica passam a atuar, de forma que o desgaste no trabalho se torna tanto mais grave quanto piores as condições de vida.

Concordamos com o argumento de Seligmann-Silva (1995) de que o modelo focado no conceito de desgaste mental pode ser tomado como um paradigma integrador. Em tal modelo articulam-se os fatores "objetivados" pelos estudos do workstress, aos fatores microssociais ou intermediários e aos macrossociais, de modo a preencher lacunas presentes tanto na abordagem positivista como na abordagem dejouriana.

Não obstante o enfoque pluridimensional do modelo do desgaste, a organização do trabalho é apontada pela autora como a esfera preponderante das determinações dos agravos psíquicos relacionados ao trabalho. A pesquisadora aponta que os estudos de saúde mental e trabalho voltados à compreensão da organização do trabalho - que envolvem diferentes "especialistas", tais como engenheiros de produção, sociólogos do trabalho, administradores, psicólogos do trabalho e ergonomistas - compreendem, de modo geral, que tensão, fadiga, medo e apatia podem ser "fabricados" (aspas da autora) pelas seguintes situações de trabalho: rígida estruturação hierárquica e de decisão de tarefas; estrutura temporal extenuante (trabalhos em turnos alternados ou de longas jornadas), políticas de pessoal e formas de gerenciamento adotadas (SELIGMANN-SILVA, 1995, p.290).

Ainda em relação aos modelos de organização do trabalho, Seligmann-Silva (1995, p. 290) observa que "quanto menor a participação do trabalhador na formulação da organização de sua própria atividade e no controle sobre a mesma, maiores as possibilidades de que esta atividade seja desfavorável à saúde mental”, argumento este tributário às postulações de Dejours (1992; 1993; 1994; 2004b).

Lima (2002) alerta para uma série de questões relevantes para os pesquisadores da área de saúde mental e trabalho. Aponta para a importância de uma psicopatologia do trabalho com ênfase na dimensão social. Considera que a perspectiva de Le Guillant (1984, citado por Lima, 2002, pp.59-62) seria exemplar no que diz respeito à construção de uma psicopatologia social. A perspectiva sociogênica diferencia-se da abordagem organossocial de Sivadon (citado por Lima, 2002, p.56ss.) e da de Dejours (1992, citado por Lima, p.63-74), esta última por ela compreendida como "idealista" e "especulativa" (Lima, 2002, p.73). Ainda que não concordemos com tais adjetivações, parecem-nos fundamentais suas considerações acerca da imprescindibilidade de considerarmos o contexto econômico, social e político do trabalho, a articulação dialética entre o subjetivo e o objetivo e os aspectos ergonômicos da atividade trabalho. Ademais, consideramos pertinente a visão dessa autora de que as pesquisas em saúde mental e trabalho devam adotar um método pluridimensional de pesquisa, ou seja, que possam lançar mão de procedimentos diversos, tais como: observações da atividade trabalho; questionários, entrevistas individuais e grupais, dados estatísticos e epidemiológicos, estudos de caso, histórias de vida. Em outras palavras, consideramos fundamentais suas considerações acerca da necessidade de evitar o reducionismo psicologizante e de articular a análise ergonômica do trabalho à análise psicossociológica do mesmo, haja vista nosso objetivo de consolidação de métodos de análise psicossocial laboral voltados à transformação da gestão patogênica do trabalho.

Heloani e Lancman (2004) ressaltam, por sua vez, em artigo intitulado Psicodinâmica do Trabalho: o método clínico de intervenção e de investigação, que a visão teórica de Dejours 
(1992; 2004a) e sua proposta metodológica coadunam-se, respectivamente, a uma visão do sujeito no trabalho que supera o reducionismo idealista psicologizante e que integra a perspectiva crítica materialista-dialética da pesquisa-ação de Thiollent (1997, citado por HELOANI; LANCMAN, 2004). De acordo com Heloani e Lancman (2004), compreendemos que a Psicodinâmica do Trabalho é um método específico que, além de ligar a intervenção institucional à pesquisa, busca compreender os aspectos psíquicos e subjetivos mobilizados pelas relações na organização do trabalho. Segundo nossa compreensão, a proposta teórica e metodológica de Dejours (1992; 1993; 2004a) envolve a escuta (coletiva) de quem executa o trabalho, de forma a propiciar um processo de reflexão realizado pelo conjunto de trabalhadores. Os processos de reflexão são geradores de mobilização entre os trabalhadores, no sentido de tornar o trabalho mais saudável (DEJOURS, 1993). Sendo assim, a Psicodinâmica do Trabalho propõe um método de investigação qualitativo voltado ao estudo e à intervenção em situações de trabalho. Parte-se do pressuposto de que a intervenção, em situações de trabalho que geram sofrimento, é de fundamental importância para a compreensão das relações entre as formas de organização de trabalho e os processos de adoecimento.

A proposta dejouriana caracteriza-se como uma abordagem crítica e qualitativa do tema subjetividade, poder e trabalho que, conforme conduzida, assume as feições dos estudos de caso e/ou das pesquisas-ação (HELOANI; LANCMAN, 2004). Vale lembrar que as abordagens qualitativas de pesquisa incluem as modalidades de pesquisa documental (materiais escritos), etnografia (compreensão das significações culturais) e estudo de caso. Este último caracterizase como compreensão singular dos eventos de uma determinada organização. A história de vida (narrativa de uma pessoa sobre sua experiência pessoal com o mínimo de interferência do entrevistador) e a observação são instrumentos utilizados tanto nos estudos de caso como nas pesquisas-ação propriamente ditas (QUEIROZ, 1987).

Segundo nossa forma de analisar a proposta metodológica de Dejours (1992; 2004a), o foco dos pesquisadores não deve se reduzir ao discurso do trabalhador e muito menos ao trabalhador enquanto indivíduo isolado. Não obstante, pesquisadores devem atentar-se aos conteúdos das falas (objeto de consenso x discussões contraditórias; dito x não dito; espontâneo $\mathrm{x}$ não espontâneo; expressões de sofrimento $\mathrm{x}$ expressões de prazer) sobre distintos temas e subtemas relacionados à atividade de trabalho, organização e gestão.

Heloani e Lancman (2004) descrevem detalhadamente as etapas do método da Psicodinâmica do Trabalho, de modo a sustentar o nosso argumento. São elas: a) Pré-enquete (construção do estudo): formação do grupo gestor da pesquisa-ação composto por trabalhadores, funcionários e pesquisadores (sendo os participantes voluntários que trabalham com a concordância da instituição); b) Enquete ou discussões grupais: ocorrem conforme a possibilidade da instituição de disponibilizar determinado conjunto de trabalhadores durante o período de trabalho, tendo o objetivo de desencadear uma reflexão e uma ação transformadora a partir da estratégia da criação de um espaço coletivo de discussão que favoreça a verbalização dos trabalhadores; c) Análise da demanda: a demanda que gera a intervenção (da direção) nem sempre é a mesma expressa pelos trabalhadores. Os pesquisadores devem reconfigurar esta demanda para que possam construir suas hipóteses e interpretações. E devem fazê-lo por meio das seguintes perguntas: O que solicita a demanda? A quem ela é dirigida? d) Análise do material da enquete: o material é apreendido com base nas verbalizações e do contexto no qual elas emergem. Ele, portanto, inclui formulações e hipóteses que os trabalhadores constroem 
sobre seu trabalho; e) Observação clínica: trata-se do registro do movimento que ocorre entre um grupo de trabalhadores e de pesquisadores ou, ainda, de um resgate ilustrado e articulado das falas, de modo a evidenciar trajetória do pensamento dos pesquisadores-coordenadores do grupo; f) Interpretação: identificação dos elementos subjetivos das sessões grupais e atribuição de sentidos aos mesmos por meio de conceitos (sofrimento/prazer no trabalho; reconhecimento; cooperação; estratégias coletivas de defesa); g) Validação e refutação: processo interativo (pesquisadores e participantes) de apresentação das interpretações dos pesquisadores e de validação da análise e das conclusões da intervenção. Fundamenta-se na estratégia de discussão do relatório das sessões (incluindo elaborações, interpretações, hipóteses, temas e comentários) com os trabalhadores-participantes, de forma a validar, refutar ou retomar seu conteúdo. Vale ressaltar que o relatório deve favorecer a reapropriação do material de pesquisa, assim como a reelaboração do saber das situações de trabalho e sua modificação; h) Validação ampliada: relatório final discutido com o conjunto de trabalhadores que não participaram diretamente da pesquisa e com a Direção, de modo a difundir as interpretações do grupo.

Os resultados esperados da pesquisa-ação também indicam uma superação do viés acrítico e psicologizante. Conforme comentam Heloani e Lancman (2004), espera-se que a pesquisa propicie: a ampliação do espaço público de deliberação sobre os processos de trabalho; a mobilização dos trabalhadores para que eles operacionalizem mudanças; a ampliação da participação dos trabalhadores em ações deliberativas; o aumento da capacidade de utilização do saber-fazer dos trabalhadores, de modo a diminuir a defasagem entre planificação e execução; a produção de acordos e compromissos negociados, de modo a favorecer a evolução e a transformação da organização do trabalho.

Portanto, consideramos ser necessária uma leitura da proposta teórico-metodológica de Dejours $(1992 ; 1993 ; 1994 ; 2004 a ; 2004 b)$ que evite o estigma de reducionista e/ou idealista. Como argumentamos, tal proposta apresenta uma abordagem pluridimensional e valoriza a interdisciplinaridade da pesquisa e o seu caráter eminentemente qualitativo. Vale lembrar que tal modalidade de pesquisa (qualitativa) congrega várias correntes do pensamento que têm como denominador o enfrentamento do modelo positivista como padrão único de ciência. $\mathrm{Na}$ pesquisa qualitativa, como procuramos demonstrar, o objeto de estudo é compreendido por meio da interpretação e da compreensão dos significados deve substituir a descrição (GAMBOA, 2000; HELOANI; LANCMAN, 2004).

\section{Por uma perspectiva histórico-dialética e psicodinâmica de pesquisas sobre saúde mental e trabalho: uma análise sobre o stress em jornalistas e guardas municipais}

Discutimos aqui o tema subjetividade, gestão e stress no trabalho a partir de uma análise comparativa de pesquisas sobre o trabalho de jornalistas (Heloani, 2003; 2005) e de guardas municipais (SILVA, 2005), de modo a ilustrar nosso argumento em prol de uma perspectiva histórico-dialética e psicodinâmica de pesquisas sobre saúde mental e trabalho.

As atividades profissionais tanto de jornalistas como de guardas municipais vinculamse à vida cotidiana. A vida cotidiana, urbana, impõe pressões econômicas, temporais, sociais, políticas, institucionais etc. Tal aspecto atinge a população de modo geral, assim como diversas categorias profissionais. Nos casos aqui em análise temos, por um lado, uma categoria profissional intelectualizada, que exerce a prática do jornalismo. Do outro, temos uma categoria 
profissional composta predominantemente pela camada social média-baixa, que exerce a prática da segurança pública e de ações de prevenção e de combate à criminalidade. Jornalistas e guardas municipais, aparentemente, habitam vidas e fatos distintos. Porém, partilham similares pressões socioeconômicas e institucionais na vida social e laboral cotidiana.

Pois bem: devemos aqui enfatizar a diferença entre o pseudoconcreto (faticidades) e o concreto (totalidade concreta) da vida cotidiana, apenas aparentemente distinta das categorias profissionais em questão: jornalistas e guardas municipais. O pseudoconcreto necessita ser diferenciado do concreto (KOSIC, 2003). Isso significa dizer que faticidades díspares estão envoltas em um mesmo cotidiano concreto e estrutural. Nele se tece a relação gestão/organização/operacionalização do trabalho e stress. Mas o aspecto organizacional não é o único. Verificamos, no cotidiano estrutural, constantes reajustamentos psicossociais experienciados pelas categorias profissionais em questão (mudanças relativas ao trabalho, família, vínculo conjugal, atividades sociais e demais processos psicossociais qualitativamente distintos). Os índices de reajustamento social em ambas as categorias profissionais são significativos e correlativos à porcentagem, também significativa, de stress, a saber: $77 \% \mathrm{em}$ jornalistas (HELOANI, 2003) e 32\% em guardas municipais (SILVA, 2005). Tal condição revela-se como preocupante, sobretudo quando analisamos aspectos qualitativos que vão além dos dados quantitativos ou passíveis de mensuração.

A gestão do trabalho e o indivíduo no mundo instituído: eis elementos que aproximam o cotidiano estrutural de jornalistas e guardas municipais - ainda que se dê por esferas (privada e pública) e modos de operacionalização do trabalho distintos. Apesar da faticidade distinta, une-os o estruturalismo da organização e gestão do trabalho que no pós-fordismo (HELOANI, 1996) nega a subjetividade, desta feita a título de reconhecê-la (ENRIQUEZ, 1995; PAGÈS, 1987). Para Enriquez (1995), a transposição da negação taylorista-fordista à instrumentalização pós-fordista da subjetividade mantém os ditames da razão instrumental à da gestão que promove o instituído em detrimento do instituinte (LOURAU, 1975).

O produto da relação gestão-indivíduo e/ou da relação indivíduo/organização nos casos mencionados e aqui em análise é o stress. Aspectos macrossociais (sócio-organizacionais), psicossociais (cotidiano estrutural) e características da atividade de trabalho são fatores determinantes do(s) significativo(s) índice(s) de stress.

As análises aprofundadas da subjetividade relacionada ao stress, trabalho e relações de poder não emergem dos dados quantitativos derivados dos instrumentais de detecção da porcentagem de stress (LIPP; GUEVARA, 1994), índices de reajustamento psicossocial (HOLMES; RAHE, 1967) e/ou de qualidade de vida (LIPP; ROCHA, 1994), mas sim das entrevistas individuais e grupais semiestruturadas (grupos focais) e relatos reiterados dos trabalhadores acerca de suas trajetórias pessoais e profissionais (histórias de vida).

Podemos afirmar que o stress de jornalistas e de guardas municipais, ambos imersos num cotidiano institucional e estrutural, é um produto da gestão do trabalho e dos processos de precarização social e laboral que denominamos como "desgaste da realidade socioinstitucional" (SILVA, 2005; HELOANI; SILVA, 2006). Tais processos implicam reajustamentos psicossociais que pressionam para "adaptações", as quais colocam em risco a saúde mental no trabalho. Determinadas atitudes e estruturas psíquicas podem intensificar tais riscos, mas não são seus artífices. O stress envolve uma dialética entre o desgaste socioinstitucional e o biopsíquico. Uma conceituação revitalizada do stress não se caracteriza 
pela ênfase na descrição sintomática ou etiológica e de suas relações com o cognitivo, como verificamos na abordagem comportamental ou neocognitivista (LIPP, 1996; 2000).

Segundo nossa compreensão, o stress revela-se como movimento de questionamento da organização e dos ditames ideológicos e de poder inseridos no cotidiano estrutural da vida socioprofissional. Se por um lado é produto de formas de gestão, por outro é grito político que pode se fazer voz da história, desejo instituinte. É desejo potencialmente instituinte, ainda que possa ser, direta ou indiretamente, produto do instituído (SILVA, 2005; LOURAU, 1975).

As pesquisas realizadas com jornalistas (HELOANI, 2003; 2005) e com guardas municipais (Silva, 2005) foram realizadas por meio de procedimentos similares e pautadas em referenciais teóricos e pressupostos metodológicos comuns. O pressuposto teórico era o de que haveria uma relação entre processos subjetivos, gestão institucional e relações de poder. Buscava-se elucidar relações nem sempre visíveis - e por vezes até negligenciadas pelo viés organizacional (BORGES, 1997) - entre gestão, saúde mental e trabalho.

No estudo com jornalistas foram entrevistados quarenta e quatro jornalistas (HELOANI, 2003; 2005). As entrevistas foram semiabertas e em profundidade, em grupo (grupos focais) e individuais recorrentes (história de vida). Foram aplicados instrumentos que permitiram a coleta de dados quantitativos: o Inventário de Sintomas de Stress (ISS), validado por Lipp e Guevara (1994), a Escala de Reajustamento Social de Holmes e Rahe (1967) e o Inventário de Qualidade de Vida (LIPP; ROCHA, 1994).

A pesquisa com os guardas municipais foi realizada com 238 sujeitos de um total de 412 da corporação. Foram entrevistadas vinte e seis equipes (grupos focais). Entrevistas individuais semiabertas foram realizadas com quarenta e dois guardas. Na maioria dos casos eram guardas identificados como estressados. Utilizou-se também o ISS (LIPP; GUEVARA, 1994), a Escala de Reajustamento Social (HOLMES; RAHE, 1967) e o SRQ-20 (SILVAFILHO, PALÁCIOS, JARDIM, RAMOS, 1997). Tais instrumentos constituíram um questionário que também incluiu questões relacionadas à saúde e à vida familiar e profissional dos entrevistados, aplicado antes da realização dos grupos focais. Posteriormente, foram feitas outras entrevistas grupais, precedidas novamente por um questionário, por meio do qual se buscou pesquisar as relações entre o stress e os problemas da formação técnico-profissional. O pressuposto foi o de que a formação era um elemento da gestão e da organização do trabalho que, ao lado dos aspectos psicossociais e sócio-organizacionais, constituía-se como fator de stress (SILVA, 2005).

$\mathrm{Na}$ análise dos dados da pesquisa com os guardas municipais argumentamos que o stress implicava uma tentativa de superar a negação da subjetividade pela gestão (SILVA, 2005). O discurso do sujeito estressado foi compreendido como um discurso crítico à instituição, à gestão e à organização do trabalho que tinha a potencialidade de transformá-las. Porém, tal intenção potencialmente transformadora não se concretizou.

No caso dos guardas municipais, o discurso do sujeito estressado engendrava críticas pertinentes à gestão da formação profissional e às ambiguidades do ordenamento jurídicoinstitucional a respeito de questões fundamentais da atividade trabalho, como, por exemplo, o uso de armas e o poder de polícia. As relações de poder entre as instituições de tal ordenamento (sistema macrojurídico policial) impediam uma melhor nitidez dos direitos e dos deveres das Guardas Municipais e das funções dos guardas municipais (PASCHOAL, 2003). Tal fato redundava em conflitos (sociais e psíquicos) de identidade (institucional e individual), que 
acalentavam a condição de stress, ou seja, de desgaste biopsíquico e socioinstitucional (HELOANI; SILVA, 2006).

Na pesquisa com jornalistas, intitulada Mudanças no mundo do trabalho e impactos na qualidade de vida do jornalista (HELOANI, 2003), verificou-se que a vida pessoal dos mesmos é geralmente precária, com falta de relacionamento familiar por conta das excessivas jornadas de trabalho e vínculos afetivos que se desfazem rapidamente. Eles trabalham em quase todos os finais de semana, mas em compensação resistem bem ao estresse. Dedicam-se à profissão e nutrem por ela uma relação ambivalente. Nas redações, o ritmo de trabalho a que se submetem é estafante, com jornadas de doze horas ou mais, estando expostos ao assédio moral, sexual e ao rígido controle social.

É possível afirmar que jornalistas recebem salários não condizentes com o grau de exigência que lhes é imposto pelas chefias. Enfrentam um ambiente altamente competitivo e condições de trabalho precárias em muitas redações. Muitos entrevistados não tinham suficiente consciência da importância social de seu trabalho. Alguns eram individualistas em excesso e pareciam influenciados pela imagem glamorosa da sociedade pela profissão.

As análises dos dados das pesquisas indicaram que idealização acerca da atividade profissional tem um duplo aspecto: por um lado gera frustração, face à realidade concreta da atividade profissional e das adversidades socioinstitucionais; por outro, a idealização enquanto desejo de transformação mantém a força de resistência contra as adversidades socioinstitucionais e biopsíquicas. Nesse sentido, mantém acesa a potencialidade crítica do sujeito estressado. Sendo assim, concordamos com Enriquez (1997) que, ao analisar os textos ditos "sociológicos" de Freud, considera que os aspectos narcísicos não apenas se relacionam às ilusões individuais, mas também aos ideais utópicos de um coletivo.

O stress, portanto, não se limita a ser uma condição individual e a resistência ao mesmo não está condicionada apenas à vitalidade biopsíquica individual. Ele é, segundo nossa compreensão, uma força de resistência política de um coletivo de profissionais a um histórico processo de desgaste social, infelizmente institucionalizado.

Embora haja um desgaste e uma instrumentalização da subjetividade no ambiente de trabalho de ambas as categorias profissionais, vale indagar: Por que não desistem de seu trabalho? Por que insistem no exercício de sua profissão? Alguns sujeitos orgulham-se de seu trabalho ou, ainda, fetichizam sua profissão. Segundo um dos jornalistas entrevistados:

Eu sempre gostei muito da minha profissão. Eu sempre fui trabalhar com muito entusiasmo. Cantarolando não, mas eu ia feliz. Quando eu estou escrevendo, eu me sinto bem. Isso me satisfaz muito. Fazer uma ligação, dar notícias e orientar o leitor. A pior coisa para um jornalista é ele não ter um fato para trabalhar, porque é a matéria-prima. (HELOANI, 2005, p.161).

Tal fala é surpreendentemente semelhante a alguns aspectos do discurso dos guardas municipais. Um dos membros de uma equipe bem entrosada e tecnicamente bem preparada verbalizou que a finalização bem sucedida de uma ocorrência policial the era extremamente "gratificante" (SILVA, 2005, p.209). O orgulho de bem servir à população era bastante enfatizado como aspecto que se contrapunha às adversidades e às frustrações vividas no cotidiano do trabalho. Os guardas também diziam que o pior não era enfrentar ocorrências de 
risco, mobilizadoras de descargas de adrenalina. O pior, para eles, era não agir, ou melhor, permanecer em algumas situações com o sentimento de inatividade, a saber: tomar conta de monumentos em praça pública; ficar estacionados por longos períodos em um mesmo local; despender muitas horas no plantão da delegacia (SILVA, 2005, p.194-226). Algumas falas foram ilustrativas: "ser vigia de estátuas?”; "ontem ficamos lá, plantados o dia inteiro”; "o que desgasta mesmo é o plantão da delegacia, a burocracia” (SILVA, 2005, p.34; p.198; p.197). Por outro lado, o poder vivenciar ocorrências de risco apresentava duas repercussões correlacionadas: uma era a de propiciar uma forte identificação com a atividade policial - por nós compreendida como atividade condizente com a identidade profissional libidinalmente investida - e a outra era a de vivência do sentimento de ser útil para com a comunidade, vivência esta que se materializava na sensação de "adrenalina pura" (SILVA, 2005, p.214). Tais situações foram referidas como prazerosas: "é gostoso, a adrenalina vai lá em cima, o giroflex ligado"; "vivemos um stress bom"; "o pessoal gosta (...) todo mundo gosta"; "é uma excitação boa”; "eu acho excitante, quero chegar lá e trocar (tiros) também”" (SILVA, 2005, p.206; p.209; p.196; p.197; p.214). Alguns chegaram a ironizar o prazer: "é o sonho de todo mundo Dr."; “tem gente que quase goza” (SILVA, 2005, p.214; p.201).

A dimensão do prazer convivia com o seu oposto, tal como no enfrentamento dos guardas com a burocracia do sistema jurídico-policial. $\mathrm{O}$ esforço de levar infratores para a delegacia era visto como vão, pois era frequente a ocorrência da liberação do apreendido (SILVA, 2005). Já os jornalistas queixavam-se que suas matérias, produto de um esforço de um jornalismo investigativo cada vez mais raro e menos reconhecido eram em $70 \%$ dos casos filtradas ou manipuladas (HELOANI, 2005). A decepção se mostrava patente nesses casos.

No caso dos guardas municipais, era também comum a queixa em relação ao que diziam “dois pesos e duas medidas" (SILVA, 2005, p.233) no que concerne à política de promoções e de punições na instituição, assim como em relação às relações de poder entre distintas instituições policiais (Guardas Municipais, Polícia Militar, Polícia Civil). Tal aspecto era similar ao de que se queixaram alguns jornalistas, ao verbalizar frases como: "há ciúmes de um lado e intrigas de outro. Eu sei que jornal é uma fábrica de intrigas..."; "tudo lá é muito tenso. Tudo é no grito. E dai eu fiquei doente...” (HELOANI, 2005).

Guardas e jornalistas são igualmente expostos com frequência ao público e à mídia. Em ambas as categorias verificamos queixas de falta de apoio ou de abandono da instituição em decorrência de processos derivados do exercício profissional. Várias equipes de guardas verbalizaram "falta de respaldo" por parte do "comando" (SILVA, 2005, p.240). O trabalho bem feito não era reconhecido como os guardas desejavam, ao passo que os percalços e equívocos eram bem criticados. Nas palavras de um jornalista evidenciamos algo similar: " $a$ maioria dos jornalistas sofre processos...”; “nunca fui processado, mas já testemunhei em processo de colegas” (HELOANI, 2005, p.158).

Julgamos pertinente considerar as limitações das pesquisas aqui referidas. Elas não se caracterizaram como pesquisas-ação organicamente vinculadas aos interesses e lutas dos trabalhadores. Não obstante, suas análises podem subsidiar pesquisas que venham assumir tal compromisso. Neste caso haveria a necessidade de pesquisa de longo prazo que favorecesse o cruzamento entre interpretações de pesquisadores e o coletivo de trabalhadores de forma intensa e efetivamente interativa. 


\section{Considerações finais}

O campo das Ciências Sociais e das pesquisas em saúde mental e trabalho, em particular, podem redundar em análises enriquecidas quando dados quantitativos e qualitativos são analisados, assim como quando são consideradas as possibilidades de interlocução de distintos modelos teóricos, desde que o façamos com a devida cautela e rigor.

De nossa parte, com base na proposta do paradigma integrador de Seligmann-Silva (1995; 2011), pudemos, por meio de considerações teóricas e da ilustração de pesquisas com jornalistas e guardas municipais, apontar para a relevância de uma proposição que conjugue a perspectiva histórico-dialética e a psicodinâmica, de modo que as relações entre subjetividade e sociabilidade possam ser compreendidas em suas múltiplas facetas e contradições (SILVA, 2013).

Não há conclusões inequívocas quando tratamos de subjetividade, stress e gestão sob a perspectiva aqui adotada. Há um constante (in)determinismo que deixa em aberto as possibilidades de concretização do conformismo e/ou da transformação do sujeito organizacional, ainda que, nos casos analisados o hierarquicus organizacional tenha sido predominante. Por outro lado, nos parece fundamental que os estudos do campo da saúde mental e trabalho possam ser aprimorados no sentido de uma metodologia crítica e interdisciplinar que aqui procuramos defender. $\mathrm{O}$ método escolhido pelo pesquisador deve ser o caminho a ser seguido, a bússola certeira, mas não um elmo cujo peso e dimensões nos perturbam a visão e o pensar. Tal como os gregos já nos ensinavam, Phármakon é o remédio que cura, mas em excesso pode ser o veneno que mata.

\section{Referências:}

AUBERT, N. A neurose profissional. In: J. F. Chanlat (Org.). O indivíduo na organização: dimensões esquecidas. São Paulo: Atlas, 1994. v.II, p.163-194.

BORGES, L. H. Trabalho e doença mental: reconhecimento do nexo trabalho e doença mental. In: J. F. SILVA FILHO, S. Jardim (Org.). A danação do trabalho: organização do trabalho e sofrimento psíquico. Rio de Janeiro: Te Corá, 1997. p.193-202.

CANGUILHEM, G. O normal e o patológico. $5^{\mathrm{a}}$ ed.. Rio de Janeiro: Forense Universitária, 2002.

COMTE, A. Curso de filosofia positiva (coleção os pensadores). São Paulo: Abril Cultural, 1978.

Dal Rosso, S. Mais trabalho! A intensificação do labor na sociedade contemporânea. São Paulo, SP: Boitempo, 2008.

DEJOURS, C. A metodologia em psicopatologia do trabalho. In: S. Lancman, L. Sznelwar (Org.). Christophe Dejours: da psicopatologia à psicodinâmica do trabalho. Rio de Janeiro: Fiocruz, 2004a. p.105-126.

DEJOURS, C. Patologia da comunicação: situação de trabalho e espaço público. In: S. Lancman, L. Sznelwar (Org.). Christophe Dejours: da psicopatologia à psicodinâmica do trabalho. Rio de Janeiro: Fiocruz, 2004b. p.243-275. 
DEJOURS, C. Psicodinâmica do trabalho: contribuições da escola dejouriana à análise da relação prazer, sofrimento e trabalho (2a ed.). São Paulo: Atlas, 1994.

DEJOURS, C. Inteligência operária e organização do trabalho: a propósito do modelo japonês de produção. In: H. Hirata (Org.). Sobre o modelo japonês: automatização, novas formas de organização do trabalho e de relações de trabalho. São Paulo: Edusp, 1993. p.281-309.

DEJOURS, C. A loucura do trabalho: estudo de psicopatologia do trabalho (5 $5^{\mathrm{a}}$ ed.). São Paulo: Cortez, 1992.

ENRIQUEZ, E. Prefácio. In: E. P. B. Davel, J. G. M. Vasconcellos (Org.). "Recursos" humanos e subjetividade. Petrópolis, RJ: Vozes, 1995. p.7-22.

ENRIQUEZ, E. Da horda ao Estado: psicanálise do vínculo social. Rio de Janeiro: Vozes, 1997.

GAMBOA, S. A A dialética na pesquisa em Educação: elementos de contexto. In: I. Fazenda (Org.). Metodologia da pesquisa educacional. São Paulo: Cortez, 2000. p.91-115.

GLINA, D. M. R. Modelos teóricos de estresse e estresse no trabalho e repercussões na saúde do trabalhador. In: GLINA, D. M. R.; ROCHA, L. E. (Orgs.). Saúde mental no trabalho: da teoria à prática. São Paulo: Roca, 2010.

HEGEL, G. Fenomenologia do espírito. Rio de Janeiro: Vozes, 2014.

HELOANI, J. R. Vivendo no limite: quem são os nossos formadores de opinião? Revista USP, 65, 2005. p. 148-168.

HELOANI, J. R Mudanças no mundo do trabalho e impactos na qualidade de vida do jornalista. São Paulo: FGV (NPP), 2003. Série Relatórios de Pesquisa.

HELOANI, J. R A mudança de paradigma no pós-fordismo: a nova subjetividade. Interações, 1 (2), 1996. p. 69-77.

HELOANI, J. R.; LANCMAN, S. Psicodinâmica do trabalho: o método clínico de intervenção e investigação. Revista Produção, 14 (3), 2004. p.2006. p.77-86.

HELOANI, J. R.; SILVA, E. P. e O desgaste da realidade sócio institucional, identidade e stress no trabalho de guardas municipais. In: G. Gutierrez (Org.). Qualidade de vida e fadiga institucional. Campinas, SP: UNICAMP / IPES, 2006. p.271-289.

HOLMES, T. H.; RAHE, R. The social readjustment rating scale. Journal of psychosomatic research, 11, 213-218.

JACQUES, M. da G. C. Abordagens teórico-metodológicas em saúde/doença mental \& trabalho. Psicologia e Sociedade, 15, (1).

JACQUES, M. da G. C. Identidade e trabalho: uma articulação indispensável. In: A. TAMAYO; J. E. BORGES-ANDRADE; W. CODO (Orgs.). Trabalho, organizações e cultura. São Paulo: Cooperativa de Autores Associados, 1995. p.41-47.

KARASEK, R. Job deemands, job decisions latitude, and mental strain: implications for job redesign. AdmSci $Q$, v.24, 1979. p. 285-307. 
KOSIC, K. Dialética do concreto ( $7^{\mathrm{a}}$ ed.). Rio de Janeiro: Paz e Terra, 2002.

LAURELl, A. C.; NORIEGA, M. Processo de produção e saúde: trabalho e desgaste operário. São Paulo: Hucitec, 1989.

LIMA, M. E. A. Esboço de uma crítica à especulação no campo da saúde mental e trabalho. In: M. da G JACQUES; W. CODO. (Orgs.). Saúde mental \& trabalho: leituras. Petrópolis, RJ: Vozes, 2002. p.50-81.

LIPP, M. E. N. O stress está dentro de você (2 $2^{\mathrm{a}}$ ed.). São Paulo: Contexto, 2000.

LIPP, M. E. N. (Org.). Pesquisas sobre stress no Brasil. Campinas, SP: Papirus, 1996.

LIPP, M. E. N.; GUEVARA, A. J. de H. Validação empírica do Inventário de Sintomas de Stress (ISS). Estudos de Psicologia, 11, (3), 1994. p. 43-49.

LIPP, M. E. N.; ROCHA, J. C. Stress, hipertensão arterial e qualidade de vida. Campinas, SP: Papirus, 1994.

LOURAU, R. El análisis institucional (3ª ed.). Buenos Aires: Amorortu, 1975.

LÖWY, M. Ideologias e Ciência Social: elementos para uma análise marxista. SP: Cortez, 1985 .

LUKÁCS, G. Prolegômenos para uma ontologia do ser social. São Paulo: Boitempo, 2010,

MANNHEIM, K. O problema sociológico das gerações. In: FORACCHI, Marialice M. (Org.) Karl Mannheim: Sociologia. São Paulo: Ática, 1982. p. 67-95.

MARX, K. O capital: crítica da economia política: Livro I: o processo de produção do capital. São Paulo: Boitempo, 1982.

MARX, K.; ENGELS, F. A ideologia alemã: Feuerbach. São Paulo: Hucitec, 1999.

MORIN, E. Ciência com consciência. Bertrand Brasil, 1994.

PAGÈS, M. O poder das organizações. São Paulo: Atlas, 1987.

Paschoal, J. C. O papel das guardas municipais na Segurança Pública. Revista do Ilanud, 2003, p. 157-169.

QUEIROZ, M. I. P. de. Relatos orais: do "indizível” ao "dizível”. Ciência e Cultura, 39, (3), 1987. p. 272-286.

SATO, L. Trabalho como categoria explicativa dos problemas psicossomáticos e de saúde mental. In: F. C. FERRAZ, R. M.; VOLICH, M. A. de A. C. ARANTES, (Orgs.). Psicossoma II: psicossomática psicanalítica. São Paulo: Casa do Psicólogo, 1998. p.175-180.

SCHMIDT, M. L. G.; CASTRO, M. F. de; CASADORE, M. M. Fatores psicossociais e o processo saúdeldoença no trabalho: aspectos teóricos, metodológicos, interventivos e preventivos. São Paulo: FiloCzar, 2018. 455p.

SCHMIDT, M. L. G.; BARBOSA, W. F.; PRADO, J. de A.; BERTOLOTE, J. M.; SILVA, F. T. de A.; ARCOS, V. de L.; TOLEDO, M. L. M. B. Estabelecimento de nexo de causalidade entre trabalho e adoecimento mental: impacto de fatores psicossociais. In: SCHMIDT, M. L. 
G.; CASTRO, M. F. de; CASADORE, M. M. Fatores psicossociais e o processo saúde/doença no trabalho: aspectos teóricos, metodológicos, interventivos e preventivos. São Paulo: FiloCzar. 2018. 455p.

SELIGMANN-SILVA, E. Psicopatologia e psicodinâmica do trabalho. In: R. Mendes (Org.). Patologia do trabalho. São Paulo: Atheneu, 1995. p.287-310.

SELIGMANN-SILVA, E. Desgaste mental no trabalho dominado. São Paulo: Cortez, 1994.

SELIGMANN-SILVA, E. Trabalho e desgaste mental: o direito de ser dono de si mesmo. São Paulo: Cortez, 2011. 622p.

SELYE, H. The general adaptation syndrome and the diseases of adaptation. Journal of Clinical Endocrinology, 6, (117), 1946.

SELYE, H. Stress: a tensão da vida (2 ${ }^{\mathrm{a}}$ ed.). São Paulo: Ibrapsa, 1965.

SILVA, E. P. e O stress no trabalho de guardas municipais: a dialética entre o desgaste sócioinstitucional e o bio-psíquico. 2005. Tese (Doutorado no Programa de Pós-Graduação em Educação) - Faculdade de Educação da UNICAMP, Campinas, 2005.

SILVA, E. P. e. Subjetividade e sociabilidade: reflexões sobre o trabalho e saúde do professor universitário sob uma perspectiva freudo-marxista. Advir (ASDUERJ), v. 30, p. 19-31, 2013.

SILVA FILHO, J. F. da; PALÁCIOS, M; JARDIM, S.; RAMOS, A. Validação do Self Report Questionnaire-20 (SRQ-20) numa população de trabalhadores de um banco estatal no Rio de Janeiro. In: J. F. da SILVA FILHO, S. Jardim. (Org.). A danação do trabalho: organização do trabalho e sofrimento psíquico. Rio de Janeiro: Te Corá, 1997. p.225-241.

Nota explicativa: Este artigo é uma versão ampliada e revisada do artigo:

SILVA, E. P. e; HELOANI, R. Aspectos teóricos e metodológicos da pesquisa em saúde mental e trabalho: reflexões a partir de uma análise comparativa do estresse em jornalistas e guardas municipais. Cadernos de Psicologia Social do Trabalho, v.10, n.1, p.105-120. 